\title{
ACCURACY IMPROVEMENT OF TROPOSPHERIC DELAY CORRECTION MODELS IN SPACE GEODETIC DATA. CASE STUDY: EGYPT
}

\author{
Sobhy Abdel Monem YOUNES ${ }^{1}$, Hafez Abbas AFIFY ${ }^{2}$ \\ Faculty of Engineering, Tanta University, Tanta City, Egypt \\ E-mails: ${ }^{1}$ sobhi100@yahoo.com (corresponding author); ${ }^{2}$ hafezafify@yahoo.com
}

Received 3 August 2014; accepted 28 November 2014

\begin{abstract}
The tropospheric delay still remains a limiting factor to the accuracy of space based positioning techniques. The estimation of station positioning, especially height component, which is particularly important for more applications is susceptible to errors in modeling the tropospheric delay due to correlations between the station positioning and residual troposphere delay parameters. As the demand on positioning accuracy and precision has increased, it has begun a necessary of relaying on large external data sets, rather than relatively simple models for treating the tropospheric delay. This method has been possible by advances made in numerical weather models which provide accurate representations of global atmospheric conditions and by advances in computing speed which allow us to perform a large number of computations over a short period of time. The purpose of this work is to develop a new model for estimating the tropospheric delay and then assess the benefits of applying this model at various geographic atmospheric conditions of Egypt. By comparing new model with some common models such as Saastamoinen model, Hopfield model, Niell-MF, Black \& Eisner-MF, UNB3 model and Vienna-MF, the results show that, new model for estimation tropospheric delay has an acceptable level of accuracy in describing the dry tropospheric delay in Egypt as it agrees closely with the numerical integration based model. The mean accuracy of this new model has been assessed to be about $9.64 \mathrm{~mm}$ with $\mathrm{rms} 11 \mathrm{~mm}$ at an elevation angle of $30^{\circ}$ and for an elevation angle of $5^{\circ}$, the mean accuracy is about $83.23 \mathrm{~mm}$ with $\mathrm{rms} 96.42 \mathrm{~mm}$ for atmospheric conditions of Egypt.
\end{abstract}

Keywords: tropospheric delay models, EMA, homogeneous atmosphere, Egypt.

\section{Introduction}

GPS pseudorange and carrier-phase measurements are affected by several random and systematic errors. These errors are originated from satellites, receivers and signal propagation through the atmosphere. Neutral atmosphere is consisting of the troposphere and stratosphere. The GNSS signal propagating through the bottom part of the atmosphere is refracted and bended; size of the effects is directly correlated with the troposphere density variations (Thayer 1974).

Tropospheric delay depends on the temperature, humidity and pressure. It varies with the height of receiver setup point and the type of propagation media below signal path. The propagation media affect radio signals at all frequency and cause refraction with a time delay of the arriving signals. Signals from satellites at low elevation angles travel a longer path through the troposphere than those at higher elevation angles. Therefore, the tropospheric delay is minimized at the user's zenith and maximized near the horizon. The effect is a delay that reaches $2.0-2.5 \mathrm{~m}$ in the zenith direction (satellite directly overhead) and increases approximately with the co-secant of the elevation angle, yielding about a 20-28 m delay at a $5^{\circ}$ elevation angle, about $9.30 \mathrm{~m}$ for a $15^{\circ}$ elevation angle (Brunner et al. 1993).

The tropospheric delay may be divided into dry and wet components. The dry component contributes about $90 \%$ of the total delay and wet component is about $10 \%$ (Janes et al. 1991). It can be modeled to about $2-5 \%$ using surface pressure and temperature, predicted to high degree of accuracy using mathematical models. Several mathematical models such as Saastamoinen model (Saastamoinen 1972), Hopfield model (Hopfield 1969), Goad and Goodman model 
(Good, Goodman 1974), Black model (Schuler 2000) etc, are used to predict quantity of tropospheric delay using surface meteorological measurements or default meteorological data.

Most standard tropospheric models were experimentally derived using available radiosonde data, which were mostly observed on the European and North American continents. The research results (Younes, Elmezayen 2012) shows that, for atmospheric conditions of Egypt, through comparison with numerical integration model, the mean accuracy of the Black \& Eisner mapping function (B\&E-MF) has been assessed to be about from $1646.73 \mathrm{~mm}$ at Helwan station (average data over the year) to $1995.72 \mathrm{~mm}$ at Aswan station (January) at an elevation angle of $5^{\circ}$ and, the mean accuracy of the Hopfield model has been assessed to be about from 1493.38 at Helwan station (july) to $1864.20 \mathrm{~mm}$ at Aswan station (January) and from $2588.61 \mathrm{~mm}$ at Helwan station (july) to $2912.50 \mathrm{~mm}$ at Aswan station (January) for Saastamoinen model at an elevation angle of $5^{\circ}$ (Younes 2012b).

The contribution of this work is divided into two parts. Firstly, develop new model for estimation dry tropospheric delay for elevation angles up to $5^{\circ}$ at atmospheric conditions of Egypt with high accuracies than these achieved by other classical models. New model will be dependent in surface meteorological data. In the second part, new model is assessed by comparing with some common models, such as Saastamoinen model (Saastamoinen 1972), Hopfield model (Hopfield 1969), Niell-MF (Niell 1996), B\&E-MF (Black, Eisner 1984), UNB3 model (Leonardo et al. 2004) and VMF (Boehm et al. 2006), using radiosonde data at different stations and different times of the year in Egypt. The meteorological data used in this study was taken from Egyptian meteorological Authority (EMA) as average values between 1990 and 2005.

\section{Methodology}

\subsection{Data description}

The data used in this research were collected from the Egyptian Meteorological Authority (EMA) as average values (from 1990 to 2005). These data include values of temperature, pressure and relative humidity at sea level and also include heights, temperatures and relative humidity values at 18 distinct levels of pressure. The pressure levels are $[1000,850,700,600,500,400$, $300,250,200,150,100,70,60,50,40,30,20,10] \mathrm{hPa}$, ranging from sea level to height about $32 \mathrm{~km}$. These data are available for three stations covering a large
Table 1. Stations coordinate

\begin{tabular}{|l|c|c|c|}
\hline \multicolumn{1}{|c|}{ Station } & Latitude $(\varphi)$ & $\begin{array}{c}\text { Longitude } \\
(\lambda)\end{array}$ & $\mathrm{H}(\mathrm{m})$ \\
\hline $\begin{array}{l}\text { Mersa } \\
\text { Matrouh }\end{array}$ & $31^{\circ} 52^{\prime}$ & $32^{\circ} 47^{\prime}$ & 38 \\
Helwan & $29^{\circ} 52^{\prime}$ & $31^{\circ} 20^{\prime}$ & 139.26 \\
Aswan & $23^{\circ} 58^{\prime}$ & $32^{\circ} 47^{\prime}$ & 192 \\
\hline
\end{tabular}

variety of climatic conditions in Egypt. These stations, as shown in Table 1, are Aswan which represents southern region, Helwan which represents central region and Mersa-Matrouh which represents northern region (near Mediterranean-sea). The data are available in two months for the year (January, July) as a daily averages, which represent the worst case of the atmosphere and average data over the year (as a monthly average) is also presented. To calculate numerical integration reference model with sufficient accuracy, the distances between pressure levels have to be decreased and atmospheric parameters values over $10 \mathrm{hPa}$ pressure level data have to be extrapolated.

For isothermal layers like tropopause, temperature is constant and the values of pressure with height are found using Eq.:

$$
P=P_{\circ} \exp \left(-\frac{g_{\circ} \varphi}{R_{d} T_{0}}\right) .
$$

But for other layers, linear interpolation is used for determining the temperature values using the formula of constant-Laps-rate atmosphere, which assumes that the temperature varies linearly with height (Mendes 1998):

$$
T=T_{\circ}-\beta h
$$

and the formula that represent pressure distribution with height in this layers is (Mendes 1998):

$$
P=P_{\circ}\left(\frac{T_{\circ}-\beta \varphi}{T_{\circ}}\right)^{\frac{g_{\circ}}{R_{d} \beta}},
$$

where, = he pressure at surface in $\mathrm{hPa}, \varphi=$ geopotential height in $\mathrm{Km} . \beta=$ temperature laps rate $\mathrm{K} / \mathrm{Km}$, $T_{\circ}=$ surface temperature in Kelvin. $R_{d}=$ gas constant $\left(287.05 \mathrm{~J} \cdot \mathrm{Kg}^{-1} \cdot \mathrm{K}^{-1}\right), g_{\circ}=$ surface gravity $\mathrm{m} / \mathrm{s}^{2}$.

Above the $10 \mathrm{hPa}$ pressure level the temperature values are determined by a standard model for the atmosphere (U.S. Standard atmosphere 1976).

\subsection{Numerical Integration model}

We calculated dry tropospheric delay by developing Numerical integration model, which is derived for 
three different stations in Egypt (Aswan, Helwan and Mersa Matrouh) in different time of year (January, July and average data for one year) as follow:

Firstly, we calculated refractivity as it given by Smith and Weintraub and with greater accuracy by Thayer (1974):

$$
N=K_{1}\left(\frac{P_{d}}{T}\right)+K_{2}\left(\frac{P_{w}}{T}\right)+K_{3}\left(\frac{P_{w}}{T^{2}}\right)
$$

where, $P_{d}$ is the partial pressure of dry gases in the atmosphere, $P_{w}$ is the partial pressure of water vapor, $T$ is the absolute temperature and $K_{i}$ are constants empirically determined.

The dry refractivity and wet refractivity respectively are equal to:

$$
N_{d}=K_{1}\left(\frac{P_{d}}{T}\right) \text { and } N_{w}=K_{2}\left(\frac{P_{w}}{T}\right)+K_{3}\left(\frac{P_{w}}{T^{2}}\right),
$$

where, $\mathrm{K}_{1}=77.6 \mathrm{~K} / \mathrm{mbar}, \mathrm{K}_{2}=64.8 \mathrm{~K} / \mathrm{mbar}, \mathrm{K}_{3}=$ $3.776 \cdot 10^{5} \mathrm{~K}^{2} / \mathrm{mbar}$.

Secondly, we used the Simpson's formula for numerical integration (Younes 2012b) to calculate the tropospheric delay.

At zenith the refracted path length $(S)$ equal geometric distance between receiver and satellite $(H)$ and the dry tropospheric delay could be expressed as:

$$
\begin{aligned}
& \Delta S_{z d t r o p}=10^{-6} \int_{h} N_{d} d h, \\
& \Delta S_{z d t r o p}= \\
& \frac{1}{6} \sum_{i=1}^{i=\frac{n}{2}}\left(H_{2 i}-H_{2 i-2}\right)\left(N_{d 2 i-2}+4 N_{d 2 i-1}+N_{d 2 i}\right) .
\end{aligned}
$$

At different zenith angles $(z)$ the dry tropospheric delay is expressed as:

$$
\Delta S_{d t r o p}=10^{-6} \int_{s} N_{d} \sec z d h,
$$

$\Delta S_{\text {drop }}=\frac{1}{6} \sum_{i=1}^{i=\frac{n}{2}}\left(H_{2 i}-H_{2 i-2}\right)$

$\left(N_{d 2 i-2} \sec z_{2 i-2}+4 N_{d 2 i-1} \sec z_{2 i-1}+N_{d 2 i} \sec z_{2 i}\right)$.

We used the formula in Eq. (5) and (6) to determine dry tropospheric delay and integration nodes are distributed equally from earth surface to $100 \mathrm{Km}$ height as below:

1. From surface to $26 \mathrm{Km}$ we calculate delay every $1 \mathrm{Km}$ (refractivity every $0.5 \mathrm{Km}$ ).

2. From $26 \mathrm{Km}$ to $50 \mathrm{Km}$ we calculate delay every $2 \mathrm{Km}$ (refractivity every $1 \mathrm{Km}$ ).

3. From $50 \mathrm{Km}$ to $100 \mathrm{Km}$ we calculate delay every $4 \mathrm{Km}$ (refractivity every $2 \mathrm{Km}$ ).
Accuracy of NIM results can be calculated by formula:

$$
\Delta=\frac{I_{2}-I_{1}}{15},
$$

where: $I_{1}, I_{2}$ is the value of tropospheric delay by NIM at integration nodes $h$ and $2 h$ respectively. $\Delta$ Must be acceptable level of accuracy no more than $\mathrm{mm}$.

\section{Development of the new model}

Delay of a radio signal arriving from different zenith angles caused by the neutral atmosphere can be derived from the next formula:

$$
\Delta S_{\text {trop }}=10^{-6} \int_{0}^{S} N d S,
$$

where, $s$ is the bended ray path length from the satellite to receiver.

Since $d S=d h \sec z$, then:

$$
\begin{gathered}
\Delta S_{\text {trop }}=10^{-6} \int_{H_{0}}^{H_{a}} N \sec z d h=10^{-6} \int_{H_{0}}^{H_{a}} N_{d} \sec z d h+ \\
10^{-6} \int_{H_{0}}^{H_{a}} N_{w} \sec z d h=\Delta S_{\text {drop }}+\Delta S_{\text {wrop }} .
\end{gathered}
$$

Since, $z$ is the zenith angle and $N_{d}, N_{w}$ are dry and wet index of refractivity respectively, which can be determined by Eq. (4).

According to the equation Mendeleev D.I. - Clapeyron B.E.:

$$
d h=-\frac{R_{d} T d P}{P g},
$$

where: $g$ is the acceleration due to gravity $\left(\mathrm{m} / \mathrm{s}^{2}\right), d h$ is differential height between two layers of a atmosphere, $d p$ is a differential pressure between two layers, $P$ is the atmospheric pressure in (mbar), $T$ is the temperature in degree Kelvin and $R_{d}=$ gas constant in $\mathrm{J} \cdot \mathrm{Kg}^{-1} \cdot \mathrm{K}^{-1}$.

By substituting from Eq. (9) in Eq. (8). Then dry atmospheric delay can be written by:

$$
\Delta S_{d t r o p}=10^{-6} \int_{P_{0}}^{P_{a}} N_{d} \sec z \frac{R_{d} T}{P g} d P .
$$

From eq. Froome and Essen:

$$
\begin{aligned}
\frac{N_{0} T_{0}}{P_{0}} & =\frac{N T}{P}=C_{0}=\text { Const., } \\
\Delta S_{\text {dtrop }} & =10^{-6} \frac{N_{0} T_{0}}{P_{0}} R_{d} \int_{P_{0}}^{P_{a}} \frac{d P}{g} \sec z .
\end{aligned}
$$

Use theory of a mean value with heights, we have:

$$
\Delta S_{d t r o p}=10^{-6} \frac{N_{0} T_{0}}{P_{0}} \frac{R_{d}}{g_{h}} \sec z_{h}\left(P_{0}-P_{a}\right) .
$$


Since $z_{h}$ is the mean value of zenith angle along the ray trace which changed with heights and determined by using Snell's law (Kleijer 2004) which state that:

$$
n_{i} r_{i} \sin z_{\mathrm{i}}=\text { const., }
$$

then:

$n_{0} r_{0} \sin z_{0}=n_{h} r_{h} \sin z_{h}$ and $\sin z_{h}=\frac{n_{0} r_{0} \sin z_{0}}{n_{h} r_{h}}$,

where, $\mathrm{z} 0, \mathrm{n} 0$ and $\mathrm{r} 0$ are respectively zenith angle, refractive index and geocentric distance at observation point. $z_{h}, n_{h}$ and $r_{h}$ are respectively zenith angle, refractive index and geocentric distance at each layer atmosphere. And:

$$
\begin{aligned}
& n_{h}=1+N_{h} \cdot 10^{-6} ; \\
& r_{h}=r_{0}+H .
\end{aligned}
$$

Since $N_{h}$ is index of refractivity, and $H$ is the height of atmosphere at observation point.

$g_{h}$ in formula (12) is the mean value of gravity acceleration at any point along ray tracing which changed with heights. Assume $g_{h}=g_{h 0} \cdot Q$ (Younes 2012a), where $Q$ is the factor of gravity change with height, that are received by empirical methods for conditions of atmosphere of Egypt by formula (Younes 2012a):

$$
Q=1-\frac{0.01 H}{0.0263 H^{2}-0.03398 H+46.5653},
$$

since $H$ is the heights of the atmosphere.

Analysis data for atmospheric conditions of Egypt gave that it possible to consider the value of $Q$ is constant for heights more than $44.0 \mathrm{~km}$ and equal 0.995416 .
For value $C_{0}=77.624 \mathrm{~K} / \mathrm{hPa}$, and $R_{d}=287.05 \mathrm{~J} /$ $\mathrm{Kg} \cdot \mathrm{K}$ with Eq. (12), the zenith dry delay can be written as:

$$
\Delta S_{\text {dtrop }}=22.281969 \frac{P_{0}-P_{a}}{g_{h 0} Q} \sec z_{h},
$$

where: $g_{h 0}$ is the gravity acceleration at surface for each station and can be received under the formula:

$$
\begin{aligned}
& g_{h 0}=9.7803266 . \\
& \left(1+0.00530248 \sin ^{2} \varphi-0.00000585 \sin ^{2} 2 \varphi\right),
\end{aligned}
$$

where, $\varphi$ - latitude of stations.

\section{Results}

We calculated dry tropospheric delay at zenith and at different zenith angles using new Eq. (16). The performances of new equation were determined by comparing their results with those obtained from highly accurate numerical integration model at three stations of Egypt at January, July and average data of year. The difference is shown in Table 2.

By analyzing these results, it can be seen that for zenith angles lower than $60^{\circ}$ new eq. are represent high accuracy in tropospheric delay prediction because they are more closely to NIM. At $60^{\circ}$ the mean difference between new model and NIM is about $7.14 \mathrm{~mm}$ with $\mathrm{rms}$ of $10.08 \mathrm{~mm}$.

But for zenith angle more than $60^{\circ}$, new model gave high errors by comparing with NIM. At $70^{\circ}$ zenith angle ( $20^{\circ}$ elevation angle) the mean difference between new model and NIM is about $27.89 \mathrm{~mm}$ with rms of $31.73 \mathrm{~mm}$, at $80^{\circ}$ zenith angle it is about $-281.37 \mathrm{~mm}$ with $\mathrm{rms}$ of $283.01 \mathrm{~mm}$, at $83^{\circ}$ zenith angle it is about $-801.75 \mathrm{~mm}$ with $\mathrm{rms} 803.12 \mathrm{~mm}$ and

Table 2. Mean tropospheric delay difference $(\mathrm{mm})$ between new equations and NIM

\begin{tabular}{|c|c|c|c|c|c|c|c|}
\hline Zenith angle & Mean & RMS & Max. & Zenith angle & Mean & RMS & Max. \\
\hline $0^{\circ}$ & 4.88 & 5.23 & 7.11 & $55^{\circ}$ & 6.27 & 7.67 & 15.67 \\
\hline $5^{\circ}$ & 4.66 & 4.96 & 6.62 & $60^{\circ}$ & 7.14 & 10.08 & 21.20 \\
\hline $10^{\circ}$ & 4.70 & 5.01 & 6.65 & $65^{\circ}$ & 12.11 & 16.02 & 31.40 \\
\hline $15^{\circ}$ & 4.76 & 5.08 & 6.70 & $70^{\circ}$ & 27.89 & 31.73 & 53.07 \\
\hline $20^{\circ}$ & 4.86 & 5.20 & 6.78 & $75^{\circ}$ & 77.64 & 80.18 & 110.22 \\
\hline $25^{\circ}$ & 4.97 & 5.34 & 6.87 & $80^{\circ}$ & 281.37 & 283.01 & 327.35 \\
\hline $30^{\circ}$ & 5.00 & 5.42 & 7.05 & $81^{\circ}$ & 386.21 & 387.72 & 436.22 \\
\hline $35^{\circ}$ & 5.05 & 5.54 & 7.78 & $82^{\circ}$ & 547.72 & 549.09 & 601.03 \\
\hline $40^{\circ}$ & 5.08 & 5.73 & 8.79 & $83^{\circ}$ & 801.75 & 803.12 & 864.12 \\
\hline $45^{\circ}$ & 5.21 & 6.07 & 10.23 & $84^{\circ}$ & 1232.45 & 1233.83 & 1320.49 \\
\hline $50^{\circ}$ & 5.63 & 6.62 & 12.36 & $85^{\circ}$ & 2008.56 & 2010.05 & 2139.66 \\
\hline
\end{tabular}


at $85^{\circ}$ zenith angle ( $5^{\circ}$ elevation angle) the mean difference between new model and NIM is about 2008.56 $\mathrm{mm}$ with rms of $2010.05 \mathrm{~mm}$.

For reducing errors by new Eq. (16) at zenith angle more than $60^{\circ}$ we can increase the value of $z_{h}$ by multiplying it in factor $K$, then zenith dry delay can be written as:

$$
\Delta S_{d t r o p}=22.281969 \frac{P_{0}-P_{a}}{g_{h 0} Q} \sec K z_{h} .
$$

Values of the factor $K$ can be calculated by formula:

$$
K=\frac{\arccos K z_{h}}{\arcsin z_{h}},
$$

since $\cos K z_{h}=\frac{\Delta S_{d t r o p}}{\Delta S_{d N I M}} \cos z_{h}$

and $z_{h}$ is determined by Eq. (13) and (14). $\Delta S_{d t r o p}$ which used in Eq. (19), determined by Eq. (16), $\Delta S_{d N I M}$ - by numerical integration models Eq. (5) and (6). At atmospheric conditions of Egypt, Table 3 has the values of factor $K$ at different zenith angles more than $60^{\circ}$. In order to estimate the values of factor $K$ we applied equations (18) and (19) for each station in (January, July and average data for one year) for zenith angles from $60^{\circ}$ to $85^{\circ}$. The least square estimated values for the factor $K$ for Aswan station, for Helwan station and for Mersa Matrouh station. Then the mean values are taken as average values from three stations.

By using the least square theory, the value of $K$ factor can be calculated by eq. of the best line of second degree polynomial as:

$$
K_{0}=-1.403 \sec z_{0}^{2}+67.99 \sec z_{0}-65.77
$$

since $K=1+10^{-5} K_{0}$.

At observation out of atmosphere for heights more than $100 \mathrm{~km}$, value of pressure is very small and can be neglected $\left(P_{a}=0\right)$.

With Eq. (17) zenith dry delay can be written as:

$$
\Delta S_{\text {dtrop }}=22.38458 \frac{P_{0}}{g_{h 0}} \sec K z_{h} \text {. }
$$

\subsection{Assessment of new model}

In order to assess the performance of new model (Eq. (20) and (21)), we have compared it with various common models such as Saastamoinen model, Hopfield model, Niell-MF, B\&E-MF, UNB3 model and VMF at different zenith angles. The performances were determined by comparing the dry tropospheric delay predicted by models with those obtained from highly accurate numerical integration model as presented in Tables 4-7 and in Figures 1-3.

Table 3. Mean values of the factor $\mathrm{K}$ for Egypt at different elevation angles

\begin{tabular}{|c|c|c|c|c|c|}
\hline Zenith angle & Mean value & RMS & Zenith angle & Mean value & RMS \\
\hline $60^{\circ}$ & 1.000573862 & 0.001122 & $81^{\circ}$ & 1.003110190 & 0.000285 \\
\hline $65^{\circ}$ & 1.000884343 & 0.000875 & $82^{\circ}$ & 1.003490867 & 0.000257 \\
\hline $70^{\circ}$ & 1.001243930 & 0.000712 & $83^{\circ}$ & 1.003944597 & 0.000242 \\
\hline $75^{\circ}$ & 1.001819860 & 0.000491 & $84^{\circ}$ & 1.004538184 & 0.000230 \\
\hline $80^{\circ}$ & 1.002804542 & 0.000314 & $85^{\circ}$ & 1.005326503 & 0.000230 \\
\hline
\end{tabular}

Table 4. Tropospheric delay difference (in $\mathrm{mm}$ ) between different models and NIM

\begin{tabular}{|l|c|c|c|c|c|c|c|c|c|}
\hline \multirow{2}{*}{\multicolumn{1}{|c|}{ Models }} & \multicolumn{3}{|c|}{$60^{\circ}$} & \multicolumn{3}{c|}{$65^{\circ}$} & \multicolumn{3}{c|}{$70^{\circ}$} \\
\cline { 2 - 13 } & $\begin{array}{c}\text { Mean } \\
(\mathrm{mm})\end{array}$ & $\begin{array}{c}\text { RMS } \\
(\mathrm{mm})\end{array}$ & $\begin{array}{c}\text { Max } \\
(\mathrm{mm})\end{array}$ & $\begin{array}{c}\text { Mean } \\
(\mathrm{mm})\end{array}$ & $\begin{array}{c}\text { RMS } \\
(\mathrm{mm})\end{array}$ & $\begin{array}{c}\text { Max } \\
(\mathrm{mm})\end{array}$ & $\begin{array}{c}\text { Mean } \\
(\mathrm{mm})\end{array}$ & $\begin{array}{c}\text { RMS } \\
(\mathrm{mm})\end{array}$ & $\begin{array}{c}\text { Max } \\
(\mathrm{mm})\end{array}$ \\
\hline Saastamoinen & 14.98 & 17.60 & 30.64 & 22.08 & 25.46 & 43.26 & 39.48 & 43.30 & 69.44 \\
\hline Hopfield & 10.36 & 13.59 & 28.31 & 16.04 & 19.43 & 38.90 & 29.55 & 33.85 & 60.25 \\
\hline Niell-mf & 17.32 & 20.05 & 35.03 & 27.73 & 30.45 & 49.23 & 51.15 & 53.52 & 78.24 \\
\hline VMF & 15.59 & 18.19 & 32.71 & 23.74 & 26.85 & 45.06 & 43.16 & 45.93 & 69.89 \\
\hline B\&E-mf & 14.74 & 17.32 & 31.64 & 21.86 & 25.20 & 43.21 & 39.64 & 42.63 & 66.44 \\
\hline UNB3m & 45.27 & 51.45 & 83.17 & 63.52 & 73.06 & 111.35 & 82.80 & 94.67 & 146.75 \\
\hline \multicolumn{1}{|c|}{ new model } & 9.64 & 11.00 & -20.24 & 11.45 & 13.13 & -22.68 & 14.82 & 17.30 & -26.44 \\
\hline
\end{tabular}


Table 5. Tropospheric delay difference (in $\mathrm{mm}$ ) between different models and NIM

\begin{tabular}{|l|c|c|c|c|c|c|c|c|c|}
\hline \multirow{2}{*}{ Models } & \multicolumn{3}{|c|}{$75^{\circ}$} & \multicolumn{3}{c|}{$80^{\circ}$} & \multicolumn{3}{c|}{$81^{\circ}$} \\
\cline { 2 - 11 } & $\begin{array}{c}\text { Mean } \\
(\mathrm{mm})\end{array}$ & $\begin{array}{c}\text { RMS } \\
(\mathrm{mm})\end{array}$ & $\begin{array}{c}\text { Max } \\
(\mathrm{mm})\end{array}$ & $\begin{array}{c}\text { Mean } \\
(\mathrm{mm})\end{array}$ & $\begin{array}{c}\text { RMS } \\
(\mathrm{mm})\end{array}$ & $\begin{array}{c}\text { Max } \\
(\mathrm{mm})\end{array}$ & $\begin{array}{c}\text { Mean } \\
(\mathrm{mm})\end{array}$ & $\begin{array}{c}\text { RMS } \\
(\mathrm{mm})\end{array}$ & $\begin{array}{c}\text { Max } \\
(\mathrm{mm})\end{array}$ \\
\hline Saastamoinen & 87.48 & 91.90 & 137.60 & 275.67 & 284.66 & 402.03 & 319.58 & 344.84 & 539.35 \\
\hline Hopfield & 72.52 & 75.70 & 113.78 & 242.16 & 244.89 & 309.05 & 271.29 & 277.80 & 379.26 \\
\hline Niell-mf & 113.99 & 115.99 & 151.23 & 349.75 & 351.47 & 411.07 & 465.05 & 466.76 & 535.68 \\
\hline VMF & 95.05 & 97.41 & 131.44 & 289.12 & 291.16 & 347.77 & 383.97 & 386.00 & 451.07 \\
\hline B\&E-mf & 87.90 & 90.44 & 124.45 & 275.81 & 277.94 & 335.01 & 370.99 & 373.08 & 438.83 \\
\hline UNB3m & 240.02 & 254.12 & 360.22 & 398.84 & 413.08 & 527.25 & 441.73 & 466.98 & 658.50 \\
\hline new model & 19.41 & 22.74 & 34.78 & 31.29 & 34.99 & -53.94 & 36.10 & 39.84 & -62.46 \\
\hline
\end{tabular}

Table 6. Tropospheric delay difference (in $\mathrm{mm}$ ) between different models and NIM

\begin{tabular}{|l|c|c|c|c|c|c|c|c|c|}
\hline \multirow{2}{*}{ Models } & \multicolumn{3}{|c|}{$82^{\circ}$} & \multicolumn{3}{c|}{$83^{\circ}$} & \multicolumn{3}{c|}{$84^{\circ}$} \\
\cline { 2 - 11 } & $\begin{array}{c}\text { Mean } \\
(\mathrm{mm})\end{array}$ & $\begin{array}{c}\text { RMS } \\
(\mathrm{mm})\end{array}$ & $\begin{array}{c}\text { Max } \\
(\mathrm{mm})\end{array}$ & $\begin{array}{c}\text { Mean } \\
(\mathrm{mm})\end{array}$ & $\begin{array}{c}\text { RMS } \\
(\mathrm{mm})\end{array}$ & $\begin{array}{c}\text { Max } \\
(\mathrm{mm})\end{array}$ & $\begin{array}{c}\text { Mean } \\
(\mathrm{mm})\end{array}$ & $\begin{array}{c}\text { RMS } \\
(\mathrm{mm})\end{array}$ & $\begin{array}{c}\text { Max } \\
(\mathrm{mm})\end{array}$ \\
\hline Saastamoinen & 389.84 & 451.09 & 753.36 & 957.03 & 960.56 & 1107.32 & 2396.03 & 2453.21 & 2912.50 \\
\hline Hopfield & 317.13 & 338.29 & 520.15 & 675.32 & 677.92 & 781.82 & 1473.22 & 1507.62 & 1864.20 \\
\hline Niell-mf & 637.76 & 642.21 & 753.79 & 900.80 & 902.61 & 1002.00 & 1328.90 & 1330.91 & 1457.07 \\
\hline VMF & 526.35 & 531.79 & 646.88 & 742.61 & 744.77 & 837.09 & 1095.35 & 1097.73 & 1213.79 \\
\hline B\&E-mf & 517.17 & 522.69 & 636.38 & 746.08 & 748.21 & 842.06 & 1134.19 & 1136.47 & 1254.89 \\
\hline UNB3m & 505.63 & 556.18 & 861.54 & 968.40 & 980.12 & 1154.21 & 1897.53 & 1922.78 & 2419.60 \\
\hline new model & 41.09 & 46.36 & -73.87 & 51.29 & 56.69 & -88.63 & 63.65 & 71.56 & -105.06 \\
\hline
\end{tabular}

Table 7. Tropospheric delay difference (in $\mathrm{mm}$ ) between different models and NIM

\begin{tabular}{|l|c|c|c|}
\hline \multirow{2}{*}{\multicolumn{1}{|c|}{ Models }} & \multicolumn{3}{|c|}{$85^{\circ}$} \\
\cline { 2 - 4 } & $\begin{array}{c}\text { Mean } \\
(\mathrm{mm})\end{array}$ & $\begin{array}{c}\text { RMS } \\
(\mathrm{mm})\end{array}$ & $\begin{array}{c}\text { Max } \\
(\mathrm{mm})\end{array}$ \\
\hline Saastamoinen & 2804.61 & 2806.68 & 2993.45 \\
\hline Hopfield & 1689.75 & 1692.85 & 1864.20 \\
\hline Niell-mf & 2061.62 & 2064.04 & 2233.4 \\
\hline VMF & 1700.02 & 1702.89 & 1857.2 \\
\hline B\&E-mf & 1834.97 & 1837.62 & 1995.7 \\
\hline UNB3m & 2151.13 & 2161.23 & 2419.60 \\
\hline new model & 83.23 & 96.42 & 186.73 \\
\hline
\end{tabular}

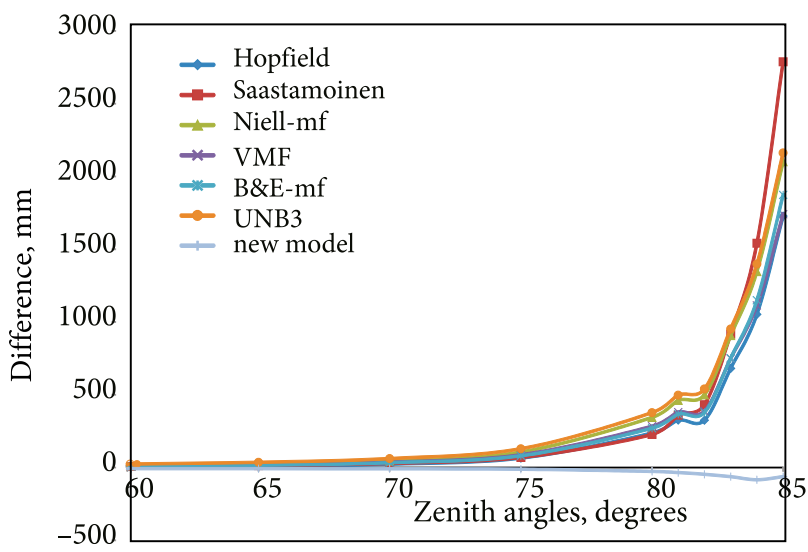

Fig. 1. Difference in $\mathrm{mm}$ for Aswan station, January

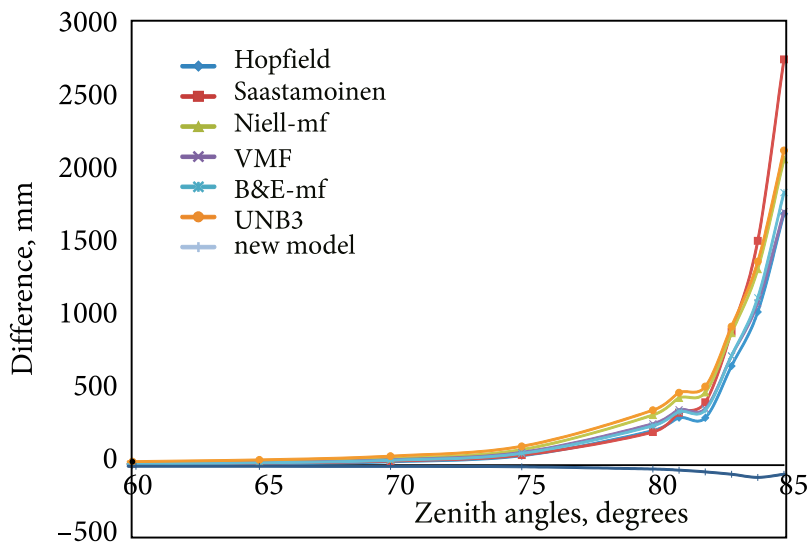

Fig. 2. Difference in $\mathrm{mm}$ for Helwan station, January

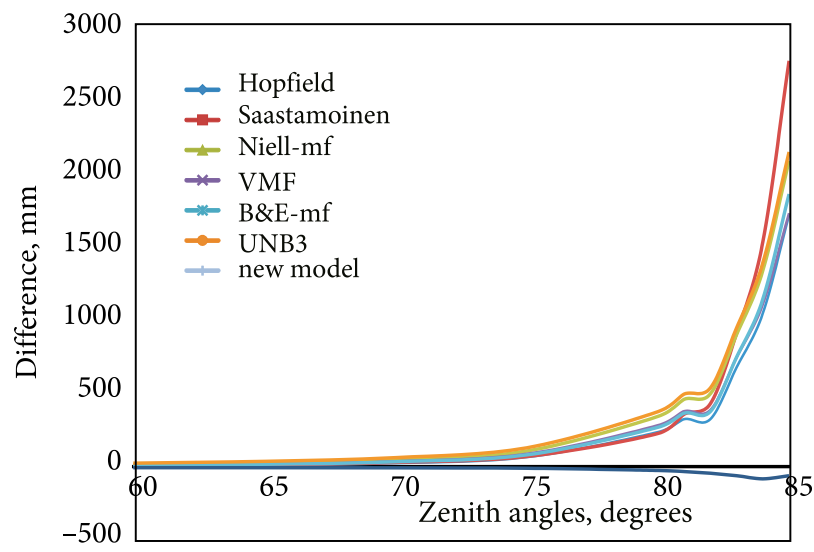

Fig. 3. Difference in $\mathrm{mm}$ for Mersa-Matrouh station, January 


\subsection{Discussion}

By analyzing these results, it can be seen that new model presents high accuracy in dry tropospheric delay prediction especially for zenith angles above 60 degree. At $60^{\circ}$ mean difference of new model and NIM is about $9.64 \mathrm{~mm}$ with rms of $11 \mathrm{~mm}$ comparing with Hopfield model which gives mean difference about $10.36 \mathrm{~mm}$ with $\mathrm{rms}$ of $13.59 \mathrm{~mm}$ and B\&E-MF which gives mean error about $14.74 \mathrm{~mm}$ with rms of $17.32 \mathrm{~mm}$. At $80^{\circ}$ mean difference of new model and NIM is about $31.29 \mathrm{~mm}$ with rms of $34.99 \mathrm{~mm}$ comparing with Hopfield model which gives mean difference about $242.16 \mathrm{~mm}$ with $\mathrm{rms}$ of $244.89 \mathrm{~mm}$ and B\&E-MF which gives mean error about $275.81 \mathrm{~mm}$ with $\mathrm{rms}$ of $277.94 \mathrm{~mm}$. At $83^{\circ}$ mean difference of new model and NIM is about $51.29 \mathrm{~mm}$ with rms of $56.69 \mathrm{~mm}$ comparing with Hopfield model which gives mean difference about $675.32 \mathrm{~mm}$ with $\mathrm{rms}$ of $677.92 \mathrm{~mm}$ and VMF which gives mean error about $746.08 \mathrm{~mm}$ with $\mathrm{rms}$ of $748.21 \mathrm{~mm}$. At $85^{\circ}$ mean difference of new model and NIM is about $83.23 \mathrm{~mm}$ with rms of $96.42 \mathrm{~mm}$ comparing with Hopfield model which gives mean difference about $1689.75 \mathrm{~mm}$ with rms of $1692.85 \mathrm{~mm}$ and VMF which gives mean error about $1700.02 \mathrm{~mm}$ with $\mathrm{rms}$ of $1702.89 \mathrm{~mm}$.

From results it can be seen that, the Hopfield model is offering the second best solution for the delay correction with the condition of availability of surface meteorological data in Egypt. B \& E - MF will be the solution with not much degraded accuracy when there is no surface meteorological data for zenith angle up to $80^{\circ}$. For small elevation angle Vienna - MF is the best to estimate tropospheric delay without needing to surface meteorological data.

\section{Conclusions}

The new tropospheric correction model has shown acceptable level of accuracy in estimation the tropospheric delay in south, center and north Egypt regions as it agrees reasonably well with the numerical integration model. So this model is recommended for tropospheric correction in this area with the condational availability of surface meteorological data.

Saastamoinen model will be the second solution with not much degraded accuracy for small zenith angle up to $30^{\circ}$, and Hopfield model will be the best solution for delay correction at small elevation angle up to $5^{\circ}$. If there is no surface meteorological data, B\&E-MF will be the solution with acceptable level of accuracy.

\section{Acknowledgements}

The author thanks all members of the Egyptian Meteorological Authority for preparing, realizing and analyzing the measurements of Temperature, Pressure and Humidity with different heights within their authority. The support of Dept. Public Works is gratefully acknowledged.

\section{References}

Black, H. D.; Eisner, A. 1984. Correcting satellite doppler data for tropospheric effects, Journal of Geophysical Research 89(D2): 2616-2626. http://dx.doi.org/10.1029/JD089iD02p02616

Boehm, J.; Werl, B.; Schuh, H. 2006. Troposphere Mapping Functions for GPS and Very Long Baseline Interferometry, from European Centre for Medium Range Weather Forecasts operational analysis data, JGR. Solid earth 111 (B2).

Brunner, F. K.; Welsh, W. M. 1993. Effect of the troposphere on GPS measurements, GPS World 4(1): 42-51.

Goad, C. C.; Goodman, L. 1974. A modified Hopfield tropospheric refraction correction model, in The American Geophysical Union Annual Fall Meeting, 12-17 December 1974, San Francisco, California.

Hopfield, H. S. 1969. Two-quadratic tropospheric refractivity profile for correcting satellite data, Journal of Geophysical Research 74(18): 4487-4499. http://dx.doi.org/10.1029/JC074i018p04487

Kleijer, F. 2004. Troposphere Modeling and Filtering for Precise GPS Leveling. Department of Mathematical Geodesy and Positioning, Faculty of Aerospace Engineering, Delft University of Technology, Netherlands.

Leonardo, R.; Marcelo, S.; Richard, B. 2004. UNB Neytral Atmosphere Models: Development and Performance. Geodetic Research Laboratory, University of New Brunswick, Frederiction, Canda.

Mendes, V. B. 1998. Modeling the neutral-atmosphere propagation delay in radiometric space techniques: $\mathrm{PhD}$ thesis, Department of Geodesy and Geomatics Engineering, University of New Brunswick, Canada.

Niell, A. E. 1996. Global mapping functions for the atmosphere delay at radio wavelengths, Journal of Geophysical Research 101(B2): 3227-3246. http://dx.doi.org/10.1029/95JB03048

Saastamoinen, J. 1972. Contributions to the theory of atmospheric refraction, Bulletin Godsique 46(3): 279-298. http://dx.doi.org/10.1007/BF02521844

Schuler, T. 2000. On ground-based GPS tropospheric delay estimation: PhD Thesis, University of Munchen. 364 p.

Thayer, G. D. 1974. An improved equation for the radio refractive index of air, Radio Science 9(10): 803-807. http://dx.doi.org/10.1029/RS009i010p00803

Younes, S. A. 2012a. Estimation of new atmospheric delay correction models in Egypt for measurement of vertical distance, Journal of American Science 8(9): 1063-1068. http://dx.doi.org/10.2478/v10156-011-0042-7

Younes, S. A. 2012b. Optimization of tropospheric delay models performance for GPS measurements in Egypt, in Al-azhar Engineering Tewelfth International Conference, 25-27 December 2012, 7(1): 131-146. 
Younes, S. A.; Elmezayen, A. G. 2012. A Comprehensive comparison of atmospheric mapping functions for GPS measurements in Egypt, Journal of Geodetic Science 2(3): 216-223.

Sobhy Abdel Monem YOUNES, Lecturer of Surveying and Geodesy, Faculty of Engineering, Tanta University, Tanta City, Egypt. E-mail: sobhi100@yahoo.com.

Research interests: GPS, Geodesy.
Hafez Abbas AFIFY, Prof. of Surveying and Photogrammetry, Faculty of Engineering, Tanta University, Alexandria City, Egypt. E-mail: hafezafify@yahoo.com.

Research interests: Remote Sensing, photogrammetry, GPS. 